\section{SPINAL EPIDURAL ABSCESS}

\author{
BY
}

ALLAN HULME, F.R.C.S.

Late Senior Registrar in Neurosurgery, South-western Regional Neurosurgical Unit, Frenchay Hospital, Bristol

\section{AND}

NORMAN M. DOTT, C.B.E., F.R.C.S.Ed., F.R.S.Ed. Professor of Neurological Surgery, University of Edinburgh

Infection of the spinal epidural fatty areolar tissue by pyogenic organisms is generally regarded as a rare condition. Although a well-recognized clinical entity, it has received little attention in British medical literature. In contrast, that of the United States contains a number of excellent reviews of the subject, notably by Dandy (1926), Gasul and Jaffe (1935), Browder and Meyers (1937, 1941), Rankin and Flothow (1946), Huesner (1948).

In 1926 Dandy found only 25 cases in the literature. Rankin and Flothow were able to review 225 cases in 1946, and two years later Huesner reported a further 20 cases.

This communication is based upon a series of 25 cases of spinal epidural suppuration, 19 of which have been treated in the department of surgical neurology, Edinburgh Royal Infirmary, between 1933 and 1952, and 6 in.the Bristol Neurosurgical centre during the past four years. In Bristol during the same period there were 21 cases of spinal tumour, 10 of which were meningioma or neurinoma. This is too small a series from which to draw deductions, but it does at any rate suggest that spinal epidural abscess is proportionally a not infrequent cause of interference with spinal cord function.

Since a presentation of the entire series would be too lengthy, the following case histories have been selected to illustrate various features of the illness.

\section{Case 1}

This case indicates the usual course of events in the acute metastatic type of infection before penicillin was available.

A youth aged 18 had malaise and fever a few hours after the extraction of an infected tooth. This was followed by an increasing low lumbar backache and pain at the back of both thighs. His temperature was $102.6^{\circ} \mathrm{F}$. $\left(39.2^{\circ} \mathrm{C}\right.$.). Acute tenderness over L 4 spinous process and severe back pain were aggravated by any movement. The abnormal neurological findings were hyperreflexia in the lower limbs, bilateral extensor plantar responses, and hyperaesthesia of the buttocks and thighs posteriorly.

The lower three lumbar laminae were removed, disclosing a localized extradural abscess containing staphylococcal pus. Pus was tracking outwards along the fourth and fifth lumbar roots. The wound was only partially closed, the central portion being left open to provide free drainage. Fever and toxaemia continued, and cerebrospinal fluid (C.S.F.) escaped from the wound. The patient died 27 days after operation.

At necropsy pus was found to have extended between the necks of the right eleventh and twelfth ribs and into the psoas sheath. A sloughing patch was found on the dura opposite the abscess and there was a generalized purulent meningitis.

\section{Case 2}

This case illustrates, in contrast, the satisfactory result ohtainable by early surgical intervention and the use of antibiotics.

A healthy girl of 9 years complained of pain in the back, of fairly sudden onset. Next day the pain extended into the left thigh. Later she became delirious and was admitted to hospital with a provisional diagnosis of tuberculous meningitis. She was found to have some weakness of the left hip flexors and a depressed left knee-jerk. The left plantar response was equivocal. Lumbar puncture yielded thick staphylococcal pus from the epidural space.

Laminectomy of the second and third lumbar vertebrae was performed, and pus was found both within and external to the vertebral canal. The wound was closed in layers with indwelling tubes for instillation of penicillin into the epidural space in doses of 20,000 units twice daily for eight days. Intramuscular penicillin, 500,000 units twice daily, was continued for two weeks. The wound healed, and the patient left hospital cured, 18 days after her admission. At a re-examination eight months after operation the only residual abnormality was very slight weakness of eversion at the left ankle.

\section{Case 3}

The disastrous results of delaying operation, despite the elimination of infection by antibiotics, are indicated in this case.

A man aged 64 gave a history of septic arthritis of the knee four years prior to his recent illness; this was followed two years later by osteomyelitis of the tibia. His spinal malady began with lumbo-dorsal backache and girdle pains round his left flank and across his abdomen. Eleven days later he developed a complete flaccid paraplegia within the space of 24 hours. He also had retention of urine.

He was retained for eight days in another hospital, where a suprapubic cystotomy was done. When he was referred to the neurosurgical department three weeks after the onset of his illness he presented a complete paralysis of the lower limbs and a sensory level on the trunk at the T 10 segmental level. The $x$-ray film showed poor definition of the left pedicle of the tenth dorsal vertebra.

A laminectomy of the eighth to the eleventh thoracic vertebrae was performed, exposing red adherent granulation tissue on the surface of the dura and a few millilitres of pale yellow pus from which a penicillin-sensitive staphylococcus was cultured. The wound was closed with indwelling catheters down which penicillin $(20,000$ units twice daily for five days) was instilled. Systemic penicillin and sulphonamide therapy was given.

The wound healed by first intention, but though postoperative lumbar puncture demonstrated a complete absence of a spinal subarachnoid block there was no improvement in the neurological state.

\section{Case 4}

Occasionally, as in this case, the abscess is very extensive and may indeed involve the entire length of the vertebral canal. Despite this a most satisfactory result may be obtained.

A healthy child aged 2 years had a trivial fall. The next day she complained of pain in her right lower limb and of headache. She was unable to walk. A week later she developed fever and signs suggestive of meningitis. Purulent fluid was obtained on lumbar puncture. The lumbar puncture was repeated next day, and on this occasion frank pus, yielding a mixed growth of Staph. aureus and Str. faecalis was obtained.

Examination revealed weakness and some extensor rigidity of the lower limbs with extensor plantar responses; sensory testing, though inaccurate in such a young patient, seemed to show a depression of pain sensation up to the level of the iliac crests. Despite the clinical evidence of meningitis, the cisternal C.S.F. contained only 10 polymorphonuclear leucocytes per $\mathrm{ml}$.

An exploration of the fenestration type was done between the laminae at L 1-2 and L 3-4 on the right side, and at L 2-3 on the left. Pus under slight pressure was released. A catheter was passed upwards extradurally through the entire length of the spinal canal, and a smaller tube down 
into the sacral region. Further pus was released by saline irrigation. The wound was closed with these tubes in situ. Penicillin was instilled down the tubes in doses of 30,000 units, at first four-hourly and later 12-hourly.

Pyrexia subsided, and within nine days active movements of the lower limbs were noted. Two months later recovery was complete.

\section{Case 5}

This case presents an entirely different clinical pattern, and illustrates not only the prolonged course which may be followed in some instances but also the fluctuation in neurological signs and difficulty in diagnosis.

A girl aged 16, whose previous health had been good apart from a crop of boils, developed pain in the left lumbar region after playing games and doing gymnastics. The pain persisted and was aggravated by movement. Two weeks later she developed tingling and numbness in the lower limbs, followed by difficulty in walking, and increasing weakness progressing to complete paraplegia. There was impairment of sensation below the umbilicus, and retention of urine. A lumbar puncture yielded C.S.F. " under decreased tension," but unfortunately no record is available of the response to jugular compression, and the protein content was not estimated.

After about three months some spontaneous return of motor power began, and continued during the next three years. Lumbar puncture was repeated eight and a half months after the beginning of her illness and then showed no block and a protein of $30 \mathrm{mg}$. per $100 \mathrm{ml}$. of C.S.F. A diagnosis of "transverse myelitis" was made. Although she remained spastic and ataxic she was able to walk and had adequate bladder control.

Twelve years after the original onset of her illness she again suffered mid-abdominal girdle pains, and 20 days later developed complete numbness and rigidity of the lower limbs and retention of urine. This increase in neurological disability took place over a period of two days. Examination showed a complete flaccid paraplegia, sensory loss below $\mathrm{T} 11$, and a complete spinal subarachnoid block. By myelography the block was localized at the level of the twelfth thoracic body.

Laminectomy $T 7$ to $T 12$ was performed, exposing dura covered with granulation tissue containing pockets of pus from which a penicillin-sensitive Staph. aureus was cultured. Normal dura was exposed above and below. The wound was closed with indwelling catheters, and treatment by local instillation of penicillin and streptomycin and systemic administration of the same antibiotics was undertaken.

During the past seven months there has been minimal return of motor and sensory functions in the lower limbs, but she remains virtually paraplegic, and no substantial improvement is anticipated.

In retrospect there seems little doubt that this patient suffered an acute attack of epidural inflammation with cord involvement at the beginning of her illness. This subsided spontaneously, perhaps aided by sulphonamide therapy, leaving a persisting low-grade infection which flared up again 12 years later without any known precipitating cause. Similar cases of prolonged duration with fluctuations in neurological disability have been recorded in the literature.

\section{Case 6}

This case of vertebral osteomyelitis was complicated by epidural suppuration.

A man aged 22 had an amputation through the left thigh for purulent arthritis of the knee and osteomyelitis of the femur. Shortly afterwards he experienced pain in the back of his neck, and noted some weakness of his right lower limb. The weakness improved for a time with massage but four and a half months later the neck pain increased and he developed paralysis of his lower limb, partial loss of sensation below the lower cervical dermatomes, and incontinence of urine and faeces.
The neurological findings tended to be somewhat variable but on the whole progressive. $X$-ray films of the cervical spine showed evidence of chronic osteitis in the form of gross erosion and new bone formation in relation to the lower three cervical vertebral bodies. A marked increase in the thickness of the prevertebral soft tissues was also apparent. Lumbar puncture demonstrated a complete subarachnoid fluid block.

On exploration a chronic extradural abscess cavity with a smooth granulating wall was found. The prevertebral swelling was also explored and a small quantity of turbid fluid evacuated.

Despite drainage, the subarachnoid block remained unrelieved, and the patient died about one month after operation. Antibiotics were not available at this time. Shortly before death he developed a suprapatellar bursitis from which Staph. albus was cultured. It therefore seems that he continued to have a persistent pyaemia.

\section{Case 7}

The course of the illness in the more chronic type of case is illustrated by the following history.

A 45-year-old man gave a seven-months history, beginning with pain below the right scapula which radiated to the lower chest and abdomen. Three months later he sustained a heavy blow on the left lumbar region and buttock, and about a month after this experienced mid-abdominal girdle pains and an electric-shock sensation in his legs. Two weeks later, gradually increasing weakness and sensory depression in the lower limbs began. There were no sphincter or constitutional disturbances.

On examination he showed a moderate paraparesis and impairment of sensation below the eighth thoracic segment. There was no spinal tenderness. Myelography demonstrated a block at the level of the seventh thoracic vertebral body, and on exploration at this level the dura was found covered with vascular granulation tissue containing minute pockets of pus from which a haemolytic streptococcus was cultured. The wound was closed with indwelling catheters and treatment with repsated local instillation of penicillin instituted.

Gradual improvement in neurological function followed, and recovery was complete in eight months.

Case 8

This case is an example of the rare type of infection giving rise to a true chronic granuloma.

A man aged 36 gave a history of typhoid fever complicated by erysipelas. Since that time, for five years, he had suffered from pains in the right hypochondrium which were attributed to indigestion.

For five months he had had girdle pains at about the ninth thoracic segmental level, worse on the right side. For six weeks he had experienced pain in the back of the right knee, and tingling paraesthesiae radiating from the right side of his body down to the right knee on coughing. Two days after the onset of these pains, weakness of both lower limbs, starting on the right, began and progressed over the next four days.

Examination showed a fit-looking man with a flaccid paraplegia and sensory "level" $\frac{1}{2}$ in. $(1.3 \mathrm{~cm}$.) below the xiphisternum. Myelography demonstrated a gradually tapering obstruction in the upper thoracic region, and at laminectomy a very vascular granuloma was exposed; this was densely adherent to the dura, and in order to relieve pressure on the cord the dura was carefully incised at the upper limit of the mass, the arachnoid being kept intact ; the incision was then carried longitudinally throughout the length of the granuloma, allowing the arachnoid to bulge through. C.S.F. was seen to pass caudally beyond the obstruction.

Histologically the granuloma consisted of chronic inflammatory tissue containing aggregations of lymphocytes, and on culture yielded a Gram-negative non-motile non-lactosefermenting bacillus which was not definitely identified. 
After transitory improvement his condition deteriorated, and lumbar puncture demonstrated a subarachnoid fluid block. Re-exploration was therefore undertaken some three weeks after the first operation. The incision through the granulation tissue was found to have refilled with the same dense inflammatory mass. This was again split longitudinally and partially excised in order to free the cord, which was found to be greatly constricted at the level of the fifth thoracic lamina. There was only minimal return of motor power, and the patient died two and a half months later. Before death, Bact. coli and streptococci were cultured from an effusion in the knee-joint, and the blood culture yielded Bact. coli.

While the granuloma in this case was never definitely proved to be due to infection with an enteric type of organism, the evidence suggests that this may have been so.

Judging from the experience in this case, simple division of the constricting granuloma would appear to be insufficient to provide lasting relief of cord compression, and it seems necessary to perform at any rate a fairly generous excision of the inflammatory tissue. Even so, nutrition of the cord may perhaps be too grossly impaired by this stage for useful recovery to ensue.

\section{Cases 9 and 10}

These are examples of cases in which infection was due to direct implantation of organisms.

Case 9.-A 39-year-old man had a lumbar puncture while under investigation for headache. Some hours later he complained of pain in the back and right thigh, and two days after this he developed pyrexia with shivering which persisted despite penicillin therapy. He was acutely tender over the lower lumbar spinous processes. Epidural suppuration was suspected and exploration performed; no pus or granulation tissue was found, but a swab taken from the extradural fat showed very large numbers of polymorphonuclear leucocytes in the smear. The wound broke down and yielded thin pus, from which no organism could be cultured. Recovery was eventually complete.

Case 10.-A soldier sustained a through-and-through thoraco-abdominal wound, with the exit wound in the left buttock. The missile traversed gut, which was repaired. The patient showed a severe lesion of the cauda equina, which failed to improve. Six months after injury the cauda equina was explored and the nerve roots were freed from scar tissue. Chronic inflammatory granulation tissue was found in the epidural space. The wound was closed with tubes for instillation of penicillin. Some improvement in neurological function followed, though he remained virtually paralysed below the knees.

\section{Aetiology and Pathology}

With rare exceptions the Staph. aureus, usually coagulasepositive, is the causative organism. It reaches the epidural space either by the blood stream or by local extension of infection.

Haematogenous infections are derived most commonly from septic skin and subcutaneous lesions such as boils and pimples, but respiratory and urinary tract infections are among the many other possible sources of organisms.

TABLE I.-Summary of Findings

\begin{tabular}{|c|c|c|}
\hline Source of Infection & No. & $\%$ \\
\hline 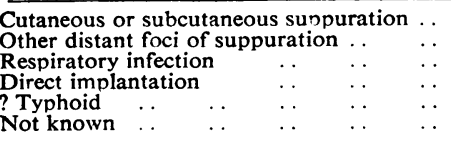 & $\begin{array}{l}8 \\
3 \\
3 \\
4 \\
1 \\
6\end{array}$ & $\begin{array}{r}32 \\
12 \\
12 \\
16 \\
4 \\
24\end{array}$ \\
\hline Total & 25 & 100 \\
\hline 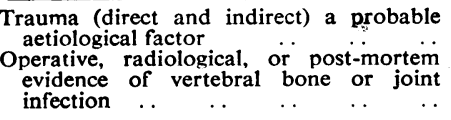 & 9 & 36 \\
\hline
\end{tabular}

Trauma to the spine seems to play a definite precipitating part in a number of instances, perhaps by producing a haematoma in which organisms may readily multiply.

Direct infections arise most commonly as a complication of vertebral osteomyelitis. Spread from a neighbouring suppurative lesion such as retropharyngeal abscess, probably by means of a spreading thrombophlebitis, also occurs. Direct implantation of organisms by wounds or a contaminated lumbar puncture needle is an obvious possibility. The relevant findings in the present series are summarized in Table I.

\section{Pathological Anatomy}

Although any level, and occasionally the entire length, of the vertebral canal may be involved, most cases of bloodborne infection are located in the upper and mid-thoracic region. This predilection is believed to depend on the anatomical distribution of the epidural tissue, which is of greatest thickness between the fourth and eighth thoracic vertebrae and again below the second lumbar vertebra, at which level a few cases occur. Anteriorly the theca is in contact with the posterior common ligament, and since the epidural areolar tissue is restricted to its dorsal and lateral aspects the infective lesion is similarly situated. In the present series 12 cases occurred in the thoracic and five in the lumbo-sacral region. The cervical region was involved in three cases, and the whole canal in one.

In the rare anteriorly placed abscesses, which occur in association with vertebral osteomyelitis, longitudinal spread is limited by adherence of the dura, but for the same reason penetration of the theca may occur, leading to a suppurative meningitis or myelitis.

In posterior abscesses there is much less resistance to axial spread, and pus and granulation tissue may extend widely along the spinal canal; usually, however, the extent is limited to a few vertebral segments. Cohen (1938) drew attention to the possibility of the formation of gravitational abscesses in the lumbo-sacral region from a primary focus at a higher level. In these common cases the dura forms a resistant barrier to the spread of infection, so that, although a C.S.F. pleocytosis of a few hundred cells is commonly found, a purulent meningitis is uncommon.

Not infrequently pus tracks outwards into the extravertebral tissue planes.

\section{Local Pathological Process}

The inflammatory reaction varies from an acute fulminating infection, with severe constitutional disturbance, to a chronic condition extending over months or even years ; it probably begins as a septic thrombophlebitis initiated by a coagulase-positive organism. In most cases vascular granulation tissue containing pockets of pus of very variable size is found. In more chronic cases there is a dense adherent granuloma, often closely resembling neoplastic tissue. These chronic granulomata are much less common than the acute and subacute varieties of infection.

Despite the resistance of the dural barrier, disastrous pathological changes soon occur in the spinal cord; these consist of liquefaction and vacuolation in the cord substance, and microscopically of all stages of degenerative change up to death and disappearance of nerve cells and disintegration of fibre tracts. It is generally believed that these changes are caused by thrombosis or stasis in blood vessels supplying or draining the cord, a view which is supported by the rapidity with which signs of cord damage progress.

In the adult, between four and ten arteries entering the cord on each side constitute the main vascular supply to their own and neighbouring segments, by way of longitudinally disposed anastomotic vessels. The venous drainage follows a somewhat similar pattern. Stasis or thrombosis in one of these important vessels is likety to produce widespread changes, which develop early in the course of the infection and progress rapidly to a stage of irreversible damage. 


\section{Clinical Features and Diagnosis Acute and Subacute}

In most cases the illness follows a fairly constant pattern of development, and the following stages may be recognized (Rankin and Flothow, 1946 ; Huesner, 1948): (1) the stage of spinal ache ; $(2)$ the stage of root pains ; (3) the stage of impairment of cord function, leading to sphincter disturbances, and early motor and sensory loss ; and (4) the stage of complete paralysis. An antecedent history of infection, frequently of a minor cutaneous nature, is often obtainable, but this is by no means invariable.

The time relations between the several stages varies. Transition from stage 3 to 4 is usually rapid, however, and may occupy only a few hours. This fact is insufficiently recognized.

The onset is often fairly rapid, and accompanied by malaise and fever. The blood shows a polymorphonuclear leucocytosis, and a positive blood culture is often obtainable.

The back pain occurs at the level of infection; it is often agonizing, and increased by movement, especially flexion as opposed to extension (Stammers, 1938).

Tenderness on spinal percussion or pressure at the appropriate level is a most important localizing sign. There may be local swelling or redness of the skin.

Root pains, sometimes accompanied by paraesthesiae, make their appearance within a few days, or, in some cases, less than 24 hours.

Headache is common, and neck rigidity and a positive Kernig's sign are often found.

In subacute cases, and those secondary to vertebral osteomyelitis, the period of spinal ache may be more prolonged and of less severity, and the onset of root pains may be delayed for a week or two.

Careful neurological examination at this early stage will often reveal reflex changes indicative of early pyramidal tract involvement. Lumbar manometry shows absent or sluggish response on jugular compression, indicating a spinal subarachnoid fluid block. The C.S.F. shows an increase in protein which is of greater degree in more chronic cases, and a pleocytosis of up to perhaps 200 cells, mostly lymphocytes. This investigation is of great importance in establishing the differential diagnosis from such non-surgical conditions as transverse myelitis, and should not be omitted. It must of course be performed with care, advancing the needle a millimetre or so at a time, and aspirating frequently lest a lumbar abscess be present. With reasonable caution there is little risk of carrying infection into the theca.

The development of stage 3, with obvious signs of impaired cord function, occurs usually within a few days of the development of root pains. Retention of urine is often an early symptom. Pain tends to diminish with development of sensory loss.

The transition to stage 4, with complete motor and sensory loss below the level of the lesion, often occurs with disastrous rapidity. In seven cases in the present series, 24 hours or less elapsed between the appearance of the first neurological abnormality and the development of stage 4.

In the chronic type of infection the course is much more prolonged, extending over months or even years; the signs of cord dysfunction may fluctuate, sometimes undergoing spontaneous remission. The constitutional phenomena of infection are absent, and the pattern of the illness closely resembles that of extramedullary spinal tumour.

The most important factor in the diagnosis of spinal epidural abscess is awareness of its possibility. The urgency and potential gravity of these cases must be more widely recognized.

No fewer than 12 cases in the present series had a virtually complete paraplegia when presented to the surgeons. It cannot be too strongly emphasized that, once signs of inter- ference with cord function begin to appear, the situation is one of extreme urgency and every hour of delay diminishes the chances of recovery.

Myelography may be required to establish the precise level of the lesion when the local and neurological evidence is equivocal in this respect.

Radiographs of the spine are not often helpful, since the infection in most cases is too recent to have caused visible changes in the bones.

\section{Treatment}

Once the diagnosis is established, exploration is urgently indicated. The objects of operation are (1) to release pus, and decompress the theca and its contents ; and (2) to provide means for repeated local application of antibacterial substances by means of thin indwelling tubes. In the first instance a limited opening into the vertebral canal should be made by removal of ligamentum flavum and portions of adjacent laminae at one or more levels. If pus in quantity is found, this will often suffice to allow insertion of thin rubber catheters to the extremities of the abscess cavity, for repeated aspiration of pus and instillation of antibiotics.

Where the lesion consists largely of granulation tissue containing small pockets of pus, a complete laminectomy should be performed throughout the length of the infected area. If the granulation tissue is thick and dense, excision by careful sharp dissection is indicated, in order to obviate subsequent stricture of the theca by scar tissue.

In children, in whom preservation of the laminae is of importance in order to avoid the later development of a kyphosis, the laminae may be elevated in a continuous string, preserving the ligaments, so that they may be replaced at the conclusion.

The catheters are brought out through stab incisions adjacent to the main wound. In the great majority of cases primary healing can be achieved, with appropriate antibiotic therapy vigorously applied locally and systemically. An early report on the culture and sensitivity of the organism is essential. It must be emphasized that antibiotics are in no sense regarded as a substitute for early and adequate surgical intervention.

\section{Results}

The prognosis with regard to survival has undergone a dramatic change since the introduction of the sulphonamide drugs and antibiotics. Previously a fatal outcome was the rule in all acute and subacute cases not treated surgically. and also in a large number of those subjected to operation (Campbell, 1937). In Huesner's series, before 1939 there were eight acute cases with three deaths: in a group of ten similar cases after 1939 there was only one death.

The prognosis for recovery of cord function bears a close relationship to the severity of neurological deficit at the time of operation. We have been unable to establish any clear correlation between the duration of paralysis and the degree of recovery. Our impression is that once conduction in the cord becomes severely compromised it is already too late to achieve any substantial degree of recovery in most cases. This does not imply, however, that the severely paralysed case should be regarded with any less urgency. since a number of remarkable recoveries have been recorded.

The results in the present series are given in Table II In Table III the severity of neurological impairment at the time of operation and the subsequent degree of functional recovery in the survivors are presented.

TABLE II.-Results

\begin{tabular}{|c|c|c|c|c|c|c|}
\hline \multirow{2}{*}{\multicolumn{2}{|c|}{ Category }} & \multirow[b]{2}{*}{ No. } & \multirow[b]{2}{*}{ Died } & \multicolumn{3}{|c|}{ Survived } \\
\hline & & & & $\begin{array}{c}\text { Full } \\
\text { Recovery }\end{array}$ & $\begin{array}{c}\text { Partial } \\
\text { Recovery }\end{array}$ & $\begin{array}{c}\text { No } \\
\text { Recovery }\end{array}$ \\
\hline $\begin{array}{l}\text { Acute } \\
\text { Subacute } \\
\text { Chronic }\end{array}$ & $\begin{array}{l}. . \\
\because .\end{array}$ & $\begin{array}{r}13 \\
7 \\
5\end{array}$ & $\begin{array}{l}4 \\
3 \\
2\end{array}$ & $\frac{4}{1}$ & $\begin{array}{l}3 \\
2 \\
1\end{array}$ & $\begin{array}{l}2 \\
2 \\
1\end{array}$ \\
\hline Total & .. & 25 & 9 & 5 & 6 & 5 \\
\hline
\end{tabular}


TABLE III

\begin{tabular}{|c|c|c|c|c|}
\hline \multirow{2}{*}{$\begin{array}{l}\text { Degree of } \\
\text { Neurological Deficit } \\
\text { Before Operation }\end{array}$} & \multirow{2}{*}{ No. } & \multicolumn{3}{|c|}{ Degree of Recovery } \\
\hline & & None & Partial & Complete \\
\hline $\begin{array}{l}\text { None or slight } \\
\text { Moderate } \quad \ldots \\
\text { Complete or very severe }\end{array}$ & $\begin{array}{l}4 \\
4 \\
7\end{array}$ & $\overline{-}$ & $\begin{array}{l}\overline{2} \\
3\end{array}$ & $\begin{array}{r}4 \\
2 \\
-\end{array}$ \\
\hline
\end{tabular}

One case in which disability was mainly due to severe trauma of the cauda has been excluded.

\section{Summary}

The results in 25 cases of spinal epidural suppuration, with illustrative case histories, are presented. The importance of recognition of the urgency and potential gravity of these cases is emphasized.

The survey indicates that, with early recognition and treatment prior to the onset of gross neurological abnormalities, satisfactory recovery can be anticipated in most cases; while delay until signs of severe cord damage become apparent usually results in permanent, crippling disability.

The most important factor in early diagnosis is an awareness of the possibility of the condition, and an appreciation of the rapidity with which the pathological process advances to an irreversible state.

Acknowledgments are due to Mr. G. L. Alexander and Mr. D. G. Phillips for permission to publish the Bristol cases and for helpful advice and criticism. Cases 1 and 4-10 are from the Edinburgh series and Cases 2 and 3 from Bristol.

\section{REFERENCES}

Browder, J., and Meyers, R. (1937). Amer. J. Surg., 37, 4

Browder, (i941). Surgery, 10, 296.

Campell, (1941). Surgery, 10, 296. . Amer. J. Surg., $37,4$.

Cohen, I (1938) (10). Surg. 108, 992 .

Cohen, I. (1938). Ann. Surg., 108, 992.

.

39. 845.

Surg, 54, 320

Stammers, E. A. R. (1938), Brit. J. Surg., 26, 366 .

\section{LOW GAMETOCYTE THRESHOLDS OF INFECTION OF ANOPHELES WITH PLASMODIUḾ FALCIPARUM,}

A SIGNIFICANT FACTOR IN MALARIA EPIDEMIOLOGY +

BY

\section{R. C. MUIRHEAD-THOMSON, D.Sc.}

Malariologists have long been familiar with the inconsistencies experienced when trying to infect anopheles with malaria parasites by feeding them on patients showing falciparum gametocytes-crescents-in the blood. Those subjects with the heaviest infections have not necessarily been the most infectious - in fact, they have sometimes proved completely non-infective. Many of these discrepancies have been attributed to the great disparity in the sex ratio of the crescents, to the possibility that the gametocytes are not "ripe," and so on Up till a few years ago, however, it was fairly generally assumed that, as the number of crescents in the blood decreased, a point was eventually reached when low density alone became a limiting factor, the subject becoming non-infective at a time when crescents could still be detected in the blood film without too much difficulty (Boyd, 1949). Those ideas seem to have been so firmly implanted that carriers with very scanty crescent infections were almost automatically rejected as a possible means of infecting anopheles in the laboratory or in the field.

Martin Young and his colleagues (1948), working with a negro population in South Carolina, showed, however, that those ideas would have to be revised considerably. They were able to infect 10 lots of Anopheles quadrimaculatus (nearly half of the total infective lots) at a time when falciparum gametocyte counts were less than 5 per c.mm. Of these, five cases had fewer than one gametocyte per c.mm.; and finally.a few mosquitoes became infected at a time when parasites were too scanty to be detected in the ordinary microscopical examination.

Similar observations, although on a much smaller scale, were made with Anopheles albimanus and a negro population in Jamaica during 1950 (Muirhead-Thomson and Mercier, 1952). These observations made a particularly deep impression on us, as at that time we were unaware of the findings in South Carolina. After feeding a batch of $\boldsymbol{A}$. albimanus on a 3-year-old subject who had previously been a good carrier and infector, routine examination of the thick film taken at the time of feeding failed to reveal a single crescent, and it was dismissed as negative. The mosquito batch was kept as a matter of curiosity, and one-third of them (12 out of 37) eventually developed gland infections. Later, another subject was found to be infective at a time when only a single crescent was present in over 200 thickfilm fields -0.12 crescents per 1,000 leucocytes, or less than 1 per c.mm.

\section{Present Investigation}

In the Gold Coast recently this work has been continued more intensively, using laboratory-bred Anopheles gambiae and working in an area west of Accra where malaria is hyperendemic. In order to find out the crescent carriers and to determine the gametocyte rate of the village populationthat is, the proportion showing falciparum gametocytes in first examination-thick blood films were examined rather more thoroughly than usual, no slide being dismissed as negative until at least 200 , and usually more, oil-immersion fields had been examined. The gametocyte rate-or rather crescent rate- of the population examined is shown in Table I.

TABLE I.-Incidence of P. falciparum Gametocytes in African Population. Weija, Gold Coast, 1952

\begin{tabular}{|c|c|c|c|c|c|}
\hline \multicolumn{3}{|c|}{$\begin{array}{l}\text { Age Group } \\
\text { (Years) }\end{array}$} & $\begin{array}{l}\text { No. } \\
\text { Examined }\end{array}$ & $\begin{array}{l}\text { No. with } \\
\text { Crescents }\end{array}$ & $\begin{array}{c}\% \text { Positive } \\
\text { (Gametocyte } \\
\text { Rate) }\end{array}$ \\
\hline $\begin{array}{c}0-1 \\
2-4 \\
5-9 \\
10-14 \\
15 \text { and over }\end{array}$ & $\begin{array}{l}\cdots \\
\cdots \\
\cdots \\
\cdots\end{array}$ & $\begin{array}{l}\ddot{*} \\
\ddot{*} \\
\cdots\end{array}$ & $\begin{array}{r}52 \\
62 \\
148 \\
78 \\
151\end{array}$ & $\begin{array}{r}21 \\
16 \\
22 \\
9 \\
9\end{array}$ & $\begin{array}{r}40 \cdot 4 \\
25 \cdot 8 \\
14 \cdot 8 \\
11 \cdot 5 \\
5.9\end{array}$ \\
\hline
\end{tabular}

Although the gametocyte rates are rather higher than usual, the general trend is similar to that found by other workers in West Africa (Barber and Olinger, 1931; Young and Johnson, 1949; Bruce-Chwatt, 1951), the higher age groups, 15 years and over, having low gametocyte rates as well as low gametocyte densities. Heavy gametocyte infections were comparatively rare, only 1 out of 491 people examined showing over 200 crescents per c.mm. Shute and Maryon (1951), in a thin-film survey in Lagos, had the same experience, only 2 out of 800 children showing 200 or more crescents per c.mm. Higher figures have been recorded elsewhere (Barber and Olinger, 1931 ; Robertson, 1945; BruceChwatt, 1951), but they are evidently exceptional. 